\title{
Vitreous Hemorrhage after Aneurismal Rupture: Terson Syndrome
}

\section{Hemorragia Vítrea após Rotura de Aneurisma Cerebral: Síndrome de Terson}

\author{
Rodrigo Becco de Souza ${ }^{1}$ Guilherme Brasileiro de Aguiar ${ }^{1}$ Sarah L.P. Weber ${ }^{1}$ \\ Juan Antonio Castro Flores ${ }^{1}$ Mario Luiz Marques Conti ${ }^{1}$ José Carlos Esteves Veiga ${ }^{1}$ \\ ${ }^{1}$ Discipline of Neurosurgery, Department of Surgery, Faculty of \\ Medical Sciences, Santa Casa de São Paulo, São Paulo, SP, Brazil \\ Arq Bras Neurocir 2018;37:163-166. \\ Address for correspondence Guilherme Brasileiro Aguiar, MD, MSc, \\ Disciplina de Neurocirurgia, Departamento de Cirurgia, Faculdade de \\ Ciências Médicas, Santa Casa de São Paulo, R. Doutor Cesário \\ Motta Jr., 61, 01221-020, São Paulo, SP, Brazil \\ (e-mail: guilhermebraguiar@yahoo.com.br).
}

\section{Abstract \\ Keywords \\ - vitreous hemorrhage \\ - cerebral aneurysm \\ - subarachnoid hemorrhage \\ - vitrectomy}

\section{Resumo}

Introduction Terson syndrome is described as an intraocular hemorrhage consequent to a spontaneous subarachnoid hemorrhage (SSAH). In the present article, we describe cases of patients who underwent neurosurgical treatment of ruptured cerebral aneurysm at our institution over a period of one year, and who were diagnosed with Terson syndrome.

Methods The present study included patients with a diagnosis of SSAH by rupture of a cerebral aneurysm who underwent treatment in our neurosurgical service from December 2009 to December 2010. The patients were followed-up for a minimum of 20 months. We have also performed a literature review and compared the data with those available in the current literature.

Results The present study included 34 patients, 18 (53\%) of which underwent endovascular treatment, and 16 (47\%) who underwent microsurgical clipping. In the sample, the mortality was $14.7 \%$ (5 patients), the same percentage of patients who were diagnosed with Terson Syndrome, which is an incidence of $14.7 \%$. Regarding the ophthalmologic evaluation, all patients had vitreous hemorrhage detected by an ultrasound examination, which was unilateral in only two patients. Visual acuity improved in all patients, being incomplete in only one of them.

Conclusion Terson syndrome is relatively common and is associated with higher mortality. With the existence of an effective treatment, it should be investigated in all patients with SSAH.

Introdução A síndrome de Terson é descrita como uma hemorragia intraocular consequente à hemorragia subaracnóidea espontânea (HSAE). O objetivo do presente artigo é descrever os casos de pacientes submetidos a tratamento neurocirúrgico de aneurisma cerebral roto diagnosticados com síndrome de Terson. received

November 16, 2015

accepted

February 2, 2016

published online

April 14, 2016
DOI https://doi.org/

10.1055/s-0036-1581085. ISSN 0103-5355.
Copyright $\odot 2018$ by Thieme Revinter

Publicações Ltda, Rio de Janeiro, Brazil
License terms

(c) (i) $\ominus$ (\$) 
Palavras-Chave

- hemorragia vítrea

- aneurisma cerebral

- hemorragia subaracnóidea

- vitrectomia
Métodos Foram incluídos no presente estudo pacientes com diagnóstico de HSAE por rotura de aneurisma cerebral submetidos a tratamento em nosso serviço de neurocirurgia no período de dezembro de 2009 a dezembro de 2010. Os pacientes foram acompanhados por um período mínimo de 20 meses. Realizamos ainda a revisão da literatura e comparamos os dados obtidos com os disponíveis na literatura atual. Resultados Foram incluídos no estudo 34 pacientes. Destes, 18 (53\%) foram submetidos a tratamento endovascular, e 16 (47\%) foram submetidos a clipagem microcirúrgica. No grupo, houve mortalidade de $14,7 \%$ (5 pacientes), o mesmo percentual de pacientes que receberam diagnóstico de síndrome de Terson. Em relação à avaliação oftalmológica, o exame de ultrassom detectou que todos os pacientes tinham hemorragia vítrea, a qual era unilateral em apenas dois pacientes. Houve melhora da acuidade visual em todos os pacientes, sendo incompleta em apenas um deles.

Conclusão A síndrome de Terson é relativamente comum, e está associada a maior mortalidade. Por ter um tratamento eficaz, deve ser investigada em todos os pacientes com HSAE.

\section{Introduction}

Terson syndrome (TS) was first described by Albert Terson in 1900 as an intraocular hemorrhage resulting from a spontaneous subarachnoid hemorrhage (SSAH) ${ }^{1,2}$ This complication presents a variable incidence, with a generally benign course, but associated with a greater morbidity and mortality when compared to patients who do not present the syndrome. ${ }^{1}$ In the present article, we describe in this article cases of patients who underwent neurosurgical treatment for ruptured brain aneurysms who were diagnosed with TS.

\section{Methods}

Patients with a diagnosis of SSAH due to rupture of a cerebral aneurysm who were submitted to treatment at our neurosurgery service from December 2009 to December 2010 were included in the present study. The treatments were performed by intracranial vascular microsurgery or endovascularly, with endovascular embolization of the aneurysms. The medical records of these patients were reviewed, and an ophthalmological evaluation was performed on all the patients who spontaneously presented complaints of visual alterations.

The patients who received the diagnosis of TS after an ophthalmologic evaluation had their evolution described. In this evaluation, visual acuity tests, fundoscopy and orbit ultrasonography were performed. We have also included the characterization of the neurological picture, as well as the findings of the imaging tests. The patients were followedup for a minimum period of 20 months. We have also reviewed the literature and compared the data obtained with those available in the current literature.

\section{Results}

A total of 34 patients diagnosed with SSAH due to cerebral aneurysm rupture were included in the present study. Of these, 18 (53\%) were submitted to endovascular treatment, and 16 (47\%) were submitted to microsurgical clipping. The total mortality rate was $14.7 \%$ ( 5 patients).

Of the 34 patients, 5 were diagnosed with TS, representing an incidence of $14.7 \%$. The mean age of the TS patients was 47 years. Regarding the neurological evaluation of these patients, we have observed that $3(60 \%)$ out of the 5 presented rupture of aneurysms of the anterior communicating complex. Most of the patients presented SSAH classified as Fisher 3, being neurologically classified as Hunt and Hess 2 ( - Fig. 1A-1B). In addition, 4 (80\%) out of these 5 patients had multiple aneurysms.

In all patients, regarding the ophthalmologic evaluation, an ocular ultrasonography detected vitreous hemorrhage (-Fig. 1C), which was unilateral in only two patients. Three patients underwent vitrectomy, and two received conservative treatment. The onset of the TS ranged from 7 to 17 days after the ictus. We have also observed that all patients had systemic arterial hypertension as a comorbidity.

In all patients, there was improvement of visual acuity, which was incomplete in only one of them. This corresponds to the final impairment of vision in one eye, of the eight initially affected. Data for each patient are shown in -Tables $\mathbf{1}$ and $\mathbf{2}$.

\section{Discussion}

Terson syndrome corresponds to a vitreous hemorrhage associated with SSAH. ${ }^{1}$ Albert Terson was a French ophthalmologist who described the clinical signs of this syndrome in a patient with SSAH in $1900 .^{2}$ Since then, some type of intraocular hemorrhage (retinal, subhyaloid or vitreous) has been documented in $10 \%$ to $40 \%$ of the individuals with $\mathrm{SSAH}^{3,4}$ while vitreous hemorrhage is reported in 3\% to $5 \%$ of cases of SSAH. ${ }^{4}$ This neurophthalmological alteration can occur from 1 hour to 47 days after the ictus. ${ }^{5}$ Among our cases, there was a variation between 7 and 17 days for the onset of the syndrome. In the literature, there is no significant difference in the incidence of the syndrome between 

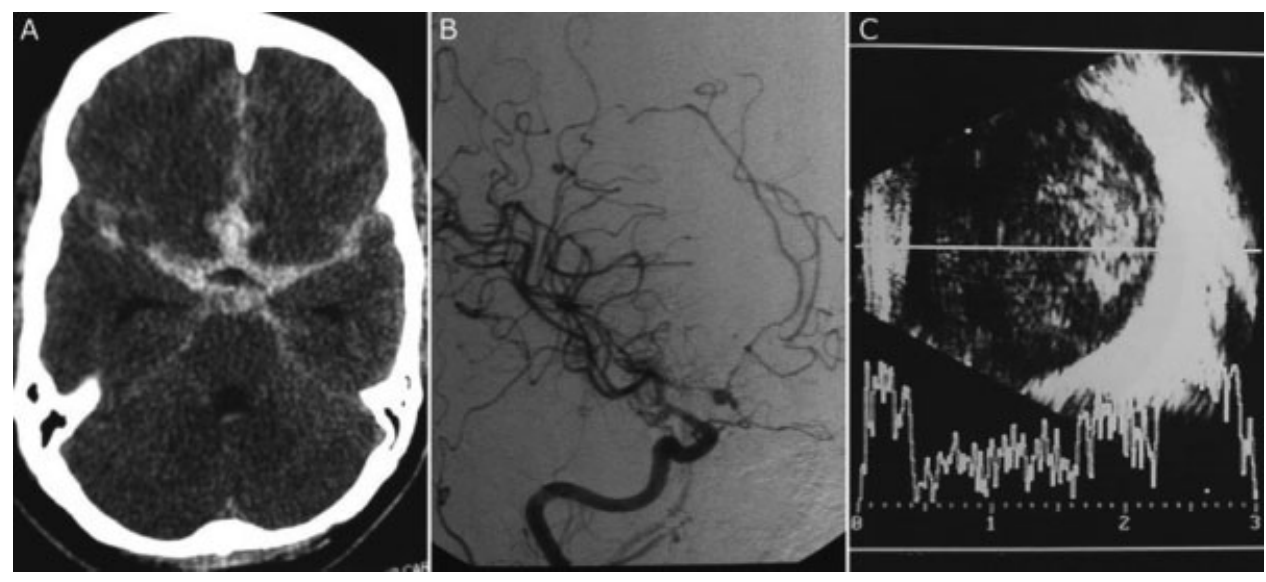

Fig. 1 (A) Computed tomography of the skull of patient 2 demonstrating diffuse subarachnoid hemorrhage, classified as Fisher 3. (B) Right carotid angiography of patient 2 demonstrating saccular aneurysm in the anterior communicating complex and vasospasm. (C) Ocular ultrasonography of patient 2 demonstrating vitreous hemorrhage.

Table 1 Characterization of patients with Terson syndrome

\begin{tabular}{|l|l|l|l|l|l|l|}
\hline Patient & Age & $\begin{array}{l}\text { Location of ruptured } \\
\text { aneurysm }\end{array}$ & $\begin{array}{l}\text { Location of other } \\
\text { aneurysms }\end{array}$ & Affected eye & Fisher scale & $\begin{array}{l}\text { Hunt and } \\
\text { Hess scale }\end{array}$ \\
\hline 1 & 38 & ACoA & ICA and MCA L & Bilateral & 3 & 2 \\
\hline 2 & 41 & ACoA & ICA R & Bilateral & 3 & 2 \\
\hline 3 & 50 & ACoA & ICA R & Right & 3 & 2 \\
\hline 4 & 58 & ACA R & - & Right & 2 & 3 \\
\hline 5 & 48 & ChA R & OftA R & Bilateral & 2 & 2 \\
\hline
\end{tabular}

Abbreviations: ACA, anterior cerebral artery; ACoA, anterior communicating artery; ChA, choroid segment of the internal carotid artery; ICA, internal carotid artery; L, left; MCA, middle cerebral artery; OftA, ophthalmic segment of the internal carotid artery; R, right.

Table 2 Clinical characterization of the Terson syndrome in the patients of the present study

\begin{tabular}{|l|l|l|l|l|}
\hline Patient & Type of treatment & $\begin{array}{l}\text { Time between SSAH } \\
\text { and TS (days) }\end{array}$ & $\begin{array}{l}\text { Visual acuity before } \\
\text { TS treatment }\end{array}$ & $\begin{array}{l}\text { Visual acuity after } \\
\text { TS treatment }\end{array}$ \\
\hline 1 & Conservative & 11 & HM-HM & $1-1$ \\
\hline 2 & Vit BE & 7 & HM-HM & $1-1$ \\
\hline 3 & Conservative & 17 & HM & 1 \\
\hline 4 & Vit RE & 17 & HM & 0.15 \\
\hline 5 & Vit BE & 10 & HM-HM & $1-1$ \\
\hline
\end{tabular}

Abbreviations: BE, both eyes; HM-HM, sees only hand motion in the affected eye; RE, right eye; SSAH, spontaneous subarachnoid hemorrhage; TS, Terson syndrome; Vit, vitrectomy.

men and women. ${ }^{6}$ However, in the present study, $80 \%$ of the patients were female.

Vitreous hemorrhage is believed to be caused by two major mechanisms. The first would be the increased intracranial pressure, which forces blood into the subarachnoid space and along the optic nerve sheath. In this way, blood would enter the sclera through a porous region and from there, into the vitreous space. ${ }^{7}$ The other explanation would be the obstruction of the venous drainage to the cavernous sinus by the increase in intracranial pressure, which would cause blood stasis and intraocular hemorrhage. ${ }^{5,8,9}$ However, this second hypothesis is disproven, since other conditions leading to increased intracranial pressure, or even pressure in the cavernous sinus, do not usually result in intraocular hemorrhage.

A systematic review study by McCarron et al. ${ }^{1}$ found that the incidence of TS in patients with SSAH ranged from $3 \%$ in retrospective studies to $13 \%$ in prospective studies. A series of 174 SSAH patients showed that TS was significantly more common among patients in more severe conditions (Glasgow coma scale $<8$ or Hunt Hess $>3$ ), who presented more severe intracranial hemorrhages (Fisher $>3$ ). ${ }^{5}$ In the present 
study, we have found a TS incidence of $14.7 \%$, which is in accordance with the data available in the literature. However, the data found in the present study are probably underestimated, since only symptomatic patients with a good neurological evolution were included.

In a prospective study by Garfinkle et $\mathrm{al}^{4}$ with 22 patients with SSAH, 4 (66.6\%) of the 6 patients with TS had an aneurysm located in the anterior communicating complex, and only 1 patient had multiple aneurysms. In another prospective study with 60 patients with SSAH, 10 had TS. ${ }^{5}$ Among the patients in this study, 30\% had an anterior cerebral artery aneurysm and $20 \%$ had an internal carotid artery aneurysm. In the present study, $60 \%$ of the patients had a ruptured aneurysm located in the anterior communicating complex. Moreover, curiously and without similarities in the literature, $80 \%$ of the patients in the present study had multiple aneurysms.

Some authors suggest that the size and number of intraocular bleeds are clinically relevant, ${ }^{10}$ as well as the relationship between the location of the intracranial hemorrhage and the unilateral or bilateral involvement of the eyes, ${ }^{11}$ and even the type of intraocular hemorrhage and mortality. ${ }^{12}$

In the aforementioned systematic review, ${ }^{1}$ the mortality of patients with TS was 4.8 times higher than that of patients without the syndrome ( $43 \%$ and $9 \%$ respectively), whereas Shaw and Landers ${ }^{13}$ concluded that the mortality among patients with the syndrome is only 2 times higher. We could not infer whether there is an increase in mortality, since our study group consists of successfully treated patients who have achieved a good neurological recovery and therefore does not include TS patients who have died.

The treatment of choice for TS is generally conservative, with improvement of visual acuity and complete resolution of the deficit within 6 months. ${ }^{5}$ However, in rare cases, proliferative retinopathy, retinal detachment or cataract may occur. ${ }^{5}$ Surgical intervention is reserved for cases in which there is no visual improvement after 6 months of the onset of the symptoms, ${ }^{5,14}$ with vitrectomy being the procedure of choice. ${ }^{15}$ This procedure, however, may be associated with complications such as: retinal damage, retinal detachment, cataract, endophthalmitis, and recurrence of retinal hemorrhage. ${ }^{5}$ Nevertheless, after a successful vitrectomy, it is expected that most patients will show complete improvement of visual acuity, ${ }^{16}$ which was observed in our patients.

In the present study, 3 (60\%) out of the 5 patients required ophthalmologic surgery (vitrectomy). Only one of the eight affected eyes did not achieve complete recovery of vision after treatment, whether conservative or surgical. Considering only the eyes submitted to vitrectomy, 4 out of $5(80 \%)$ had reversal of symptoms, with final acuity of 1 . This represents a result compatible with the literature. In a retrospective study by Garweg et al, ${ }^{17} 59.1 \%$ of the patients with TS presented a visual acuity better than 0.8 after treatment with vitrectomy.

\section{Conclusion}

Terson syndrome is relatively frequent among patients with $\mathrm{SSAH}$, and the usual clinical manifestation is reduced visual acuity. The diagnosis of TS should be early, considering its association with poor prognosis, and the reversibility of the ophthalmologic condition through surgical or even conservative management.

\section{References}

1 McCarron MO, Alberts MJ, McCarron P. A systematic review of Terson's syndrome: frequency and prognosis after subarachnoid haemorrhage. J Neurol Neurosurg Psychiatry 2004;75(03): 491-493

2 Terson A. De L'hémorrhagie dans Le corps vitre au cours de L'émorrhagie cerebrale. Clin Ophthalmol 1900;6:309-312

3 Fahmy JA. Fundal haemorrhages in ruptured intracranial aneurysms. I. Material, frequency and morphology. Acta Ophthalmol (Copenh) 1973;51(03):289-298

4 Garfinkle AM, Danys IR, Nicolle DA, Colohan AR, Brem S. Terson's syndrome: a reversible cause of blindness following subarachnoid hemorrhage. J Neurosurg 1992;76(05):766-771

5 Fountas KN, Kapsalaki EZ, Lee GP, et al. Terson hemorrhage in patients suffering aneurysmal subarachnoid hemorrhage: predisposing factors and prognostic significance. J Neurosurg 2008; 109(03):439-444

6 He T, Wu LN, Chen B, Xing YQ. [Incidence and relative factors of Terson syndrome in patients with aneurysmal subarachnoid hemorrhage]. Zhonghua Yan Ke Za Zhi 2011;47(12):1096-1101

7 Doubler FH, Marlow SB. A case of hemorrhage into the optic nerve sheath as a direct extension from a diffuse intra-meningeal hemorrhage caused by rupture of an aneurysm of a cerebral artery. Arch Ophthalmol 1917;46:533-536

8 Medele RJ, Stummer W, Mueller AJ, Steiger HJ, Reulen HJ. Terson's syndrome in subarachnoid hemorrhage and severe brain injury accompanied by acutely raised intracranial pressure. J Neurosurg 1998;88(05):851-854

9 Castren JA. Pathogenesis and treatment of Terson-syndrome. Acta Ophthalmol (Copenh) 1963;41:430-434

10 Riddoch G, Goulden C. On the relationship between subarachnoid and intraocular haemorrage. Br J Ophthalmol 1925;9(05): 209-233

11 Manschot WA. The fundus oculi in subarachnoid haemorrhage. Acta Ophthalmol (Copenh) 1944;22:281-299

12 Shaw HE Jr, Landers MB, Sydnor CF. The significance of intraocular hemorrhages due to subarachnoid hemorrhage. Ann Ophthalmol 1977;9(11):1403-1405

13 Shaw HE Jr, Landers MB III. Vitreous hemorrhage after intracranial hemorrhage. Am J Ophthalmol 1975;80(02):207-213

14 Körner F, Meier-Gibbons F. [Vitrectomy in Terson syndrome. Report of 18 cases]. Klin Monatsbl Augenheilkd 1992;200(05): 468-471(Ger.)

15 Roux FX, Panthier JN, Tanghe YM, et al. [Terson's syndrome and intraocular complications in meningeal hemorrhages (26 cases)]. Neurochirurgie 1991;37(02):106-110

16 Schultz PN, Sobol WM, Weingeist TA. Long-term visual outcome in Terson syndrome. Ophthalmology 1991;98(12):1814-1819

17 Garweg JG, Koerner F. Outcome indicators for vitrectomy in Terson syndrome. Acta Ophthalmol 2009;87(02):222-226 